\title{
Ontology Matching Approaches for eRecruitment
}

\author{
Fuad Mire Hassan \\ Faculty of Computer Science \\ and Information Systems, \\ University Technology Malaysia
}

\author{
Imran Ghani \\ Faculty of Computer Science \\ and Information Systems, \\ University Technology Malaysia
}

\author{
Muhammad Faheem, \\ Abdirahman Ali Hajji \\ Faculty of Computer Science \\ and Information Systems, \\ University Technology Malaysia
}

\begin{abstract}
Ontology researches have been carried out in many diverse research areas in the past decade for numerous purposes especially in the eRecruitment domain. In this article, we would like to take a closer look on the current work of such domain of ontologies such as eRecruitment. Ontology application for e-Recruitment is becoming an important task for matching job postings and applicants semantically in a Semantic web technology using ontology and ontology matching techniques. Most of the reviewed papers used currently (existing) available widespread standards and classifications to build human resource ontology that provide a way of semantic representation for positions offered and candidates to fulfil, some of other researches have been done created their own HR ontologies to build recruitment prototype. We have reviewed number of articles and identified few purposes for which ontology matching techniques are applied so far and how these matching techniques used in that respective domain.
\end{abstract}

\section{Keywords}

Ontology Matching, Human Resource Ontology, eRecruitment

\section{INTRODUCTION}

The World Wide Web is a fast growing medium of information and service which the people and the applications may need to be shared. Ontologies played major role in supporting the information sharing mechanism by using semantic and extended syntactic interoperability of the web. Ontology matching is a necessary for sharing and exchange information among Semantic Web applications such as job postings and application in an eRecruitment domain.

Ontology researches have been carried out in many diverse research areas in the past decade for numerous purposes. In most fields, however, useful ontological solution have been proposed and applied, while gaining a lot of researcher's attention so far. However, there are two different types of ontology [1]. Domain Ontologies provide a set of structured concepts for determining particular domain; it is applied in areas like jobs, medicine, military intelligence, agriculture, automobiles and so many other relevant areas [2]. So, domain ontology is a huge and can be contained more and more terms to interrelate. And Theory Ontologies provide a set of terms for describing some aspects of the world, which can be time, space or plans. Theory ontology is to be more likely smaller and abstract than domain ontology. Therefore, we can define ontology as a set of structured concepts or terms and relationships between them in a given specified domain.

The development of communication and information technologies has made accessible a large amount of desperate information. The challenge of managing heterogeneity between diverse information sources is increasing, however; overcoming semantic heterogeneity is naturally accomplished in two steps, including: first, matching entities to specify an alignment, i.e., a set of correspondences and second an alignment interpretation according to application needs, such as query answering or data translation. Semantic heterogeneity problem can be solved using ontology matching which finds correspondences between semantically related entities among different source of ontologies [30].

On the other hand, there are number of ontologies in various applications which cannot interoperate [3]. This is because; there can be entities which have different names in several ontologies those may use dissimilar languages in order to address the same set of terms [2]. However, ontology matching is a method used to map the different terms among ontologies [4]. Ontology matching is a technique used to find the relationships (equivalence) between entities of given ontologies; each and every ontology has a number of entities (classes, properties, rules).

The matching process specifies an alignment $\mathrm{A}$ (to be defined) for a couple of ontologies $\mathrm{O} 1$ and $\mathrm{O} 2$. According to this purpose, we believe that $\mathrm{O} 1$ and $\mathrm{O} 2$ are set of entities which are finite. Reference alignment is an association of ontologies which confirmed by domain experts [31]. OAEI (Ontology Alignment Evaluation Initiative) is a coordinated international initiative that manages evaluations of matching systems annually. Matching algorithms are evaluated according to the following measures inspired from information retrieval including precision (which is a measure of the number of correctness), recall (which is a measure of the number of completeness) and F-measure, which aggregates precision and recall $[30,31]$. However, the matching process can be viewed as a function (f) which, from a pair of ontologies $\mathrm{O} 1$ and $\mathrm{O} 2$ to match, an input alignment $\mathrm{A}$, a set of parameters $\mathrm{p}$ and a set of oracles and resources $r$, returns an alignment $A^{\prime}$ between these ontologies [5]:

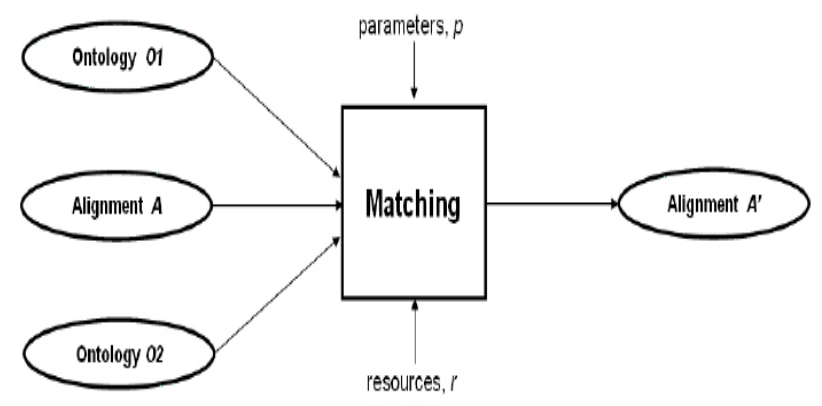

Figure 1: The Matching Process [5] 
Online job portals have grown up very fast, and the online recruitment market divided into chunks where the job seeker is unable to get information of all relevant open positions. Due to the cost of publishing job posts into the online job portals, consequently the employers publish into the portals a limited number of job advertisements which prevents the jobs offered from reaching all qualified applicants, so that, employers acquire a pool of candidates' applications for an open position [6].

The first step to develop eRecruitment is to create Human Resource Ontology which its main concept is based on "Applicant: the candidate for the job", "Employer: the organization that offered the job", "Job Description: the job offered by the employer", and "Profile: the applicant's qualification and experience information" [7]. While creating HR Ontology, they use to integrate some existing widespread standards and classifications containing clear and wellrecognized descriptions of occupational titles, associated [8].

However, job offers would like to reduce job publishing costs and they would also like to employ pre-selecting technique to select suitable candidates in order to decrease number of applicants. Applicants would like to access transparently open positions in the job market with their search statements in the online recruitment portals [6]. For those reasons, so many papers have been published talking about Semantic-ontology matching techniques within recruitment processes. In this paper, we would like to survey some of them.

This paper is organized as follows. Section 2 ontology matching techniques and classifications of eRecruitment ontologies are discussed; Section 3 finally discussion, limitations, conclusion and future work remarks are presented.

\section{ONTOLOGY MATCHING TECHNIQUES AND CLASSIFICATION OF ERECRUITMENT ONTOLOGIES}

\subsection{Ontology matching/alignment techniques}

Ontology matching is an approach to find the relationships between the items of two or more different ontologies. The goal of Ontology matching in any domain can be reached by developing a number of different techniques. Ontology matching is an approach to find the relationships between the items of two or more different ontologies using ontology matching techniques. The terms mapping, matching and alignment are frequently used in work about combining ontologies. Based on recent studies about combining ontologies, the terms are defined as follows [10].

- Ontology merging: Combines two ontologies from the same subject areas into a new ontology.

- Ontology integration: Combine two ontologies from different subject areas into a new ontology.

- Ontology alignment: Identify correspondences between the source ontologies.

- Ontology mapping: Find equal parts in different source of ontologies.

- Ontology matching: Find similar parts in the source of ontologies or finding translation rules between ontologies.
To present a conceptual basis, researchers have been carried out so many researches to specify different types of ontology matching techniques and provide basic classifications to distinguish them. So, here are some classifications of ontology matching methods [9].

i. Terminological Matching: this is computing similarities according to the string of classes and name of properties including String-based: few examples that are widely used in matchmaking systems are edit distance, and n-gram, prefix, and suffix [24], Semantic based are the semantic meaning of strings used as names of ontology concepts, the meaning of these terms is acquired from an outside source. The semantic meaning of a concept in a thesaurus is identified according to a set of possible meanings of the concept and a set of terminological relations between the concepts and other concepts [25], and Lexicons-based: are the character strings which is used as names of ontology concepts or as terms of a natural language. According to that, natural language processing techniques may be implemented to parse these strings, as it can be processed using semantic or syntactic linguistic techniques such as tokenization, lemmatization, elimination, heuristic and grammar analysis [25].

ii. Structural Level Matching computes associations by analyzing how elements or their concepts appear together in a structure. Internal Structure: this is comparing the internal configuration of entities (example. the value range). External Structure: this is comparing the correspondences of the classes with other classes. Taxonomical Structure: this is comparing the location of the entities within taxonomy. Some structural matching techniques include Similarity Flooding Algorithm which is one of structural techniques that can be issued in matching of different data structures called models (which specifies instances, schemas or both). They have changed models into direct labeled graphs. They use for the matching algorithm the concept that two graphs can be similar when their neighboring nodes of the graph are similar [26]. Another technique proposed in [27] is a structural similarity measure based on the nodes from the matching tree to reimburse the shortage of the linguistic similarity measure. It computes similarities of the ontology in two dissimilar ways. As knowledge representation language and ontologies developed, the similarity measurement is based on structural similarity required to support linguistic similarity measure to have improved matching process.

iii. Extensional Comparison (Instance) this is comparing certain extension of classes, i.e. instances of classes. Some instance matching techniques include GLUE [28] is a system that employs machine learning techniques to create semantic mappings between elements of different ontologies. It uses many learning strategies to handle with various types of information, either in instances or in the taxonomic structure of different ontologies in order to measure similarity accurately as well as another techniques proposed in [29] presented a matcher operating on ontologies of a hierarchical type largely designed in a bottom-up way for the purpose of an e-commerce application. The 
application domain of the system is a highly narrow, because it depends on the existence of a single id-key

of

every

concept

instance.

Table 1: Ontology Matching Techniques Classification

\begin{tabular}{|l|l|l|}
\hline $\begin{array}{l}\text { Ontology Matching } \\
\text { Technique }\end{array}$ & Description & $\begin{array}{l}\text { Remarks } \\
\text { Calculates and matches the similarity } \\
\text { some strings. }\end{array}$ \\
\hline Terminological & $\begin{array}{l}\text { Compares entity descriptions for each } \\
\text { ontologies (internal structure) or the } \\
\text { correspondences that each entity may have } \\
\text { with others (external structure). }\end{array}$ & $\begin{array}{l}\text { Helpful where the matching } \\
\text { comparison of the ontology is } \\
\text { based on text strings or on the } \\
\text { language. }\end{array}$ \\
\hline Structural & $\begin{array}{l}\text { Valuable technique for } \\
\text { internal structure of the } \\
\text { entities or the } \\
\text { correspondences of the } \\
\text { entities may have towards } \\
\text { other external structure } \\
\text { entities. }\end{array}$ \\
\hline Extensional (Instance) & $\begin{array}{l}\text { Compares the instance/extension or the length } \\
\text { of the classes of ontologies: in other terms, } \\
\text { class instantiations or objects }\end{array}$ & $\begin{array}{l}\text { Helpful if the information of } \\
\text { entities compared is limited } \\
\text { and needed to compare } \\
\text { additional data or support } \\
\text { other matching techniques for } \\
\text { detecting where frequently } \\
\text { erroneous or misleading } \\
\text { correspondences occur }\end{array}$ \\
\hline
\end{tabular}

Table 1 presents classification of ontology matching techniques. The goal of Ontology matching techniques in any domain can be reached by developing a number of different methods, for that reason the classifications of ontology matching techniques can be categorized as the above table contents include: Terminological, Structural and Extensional

\subsection{Classifications of eRecruitment \\ Ontologies}

In this section we survey and review the most outstanding carried research efforts for applying ontologies to the eRecruitment domain. Most of the researches, as their first step to develop eRecruitment, create Human Resource Ontology which its main concept is based on "Applicant: which is the candidate for the job", "Employer: which is the organization that offered the job", "Job Description: which is the job offered by the employer", and "Profile: which is the applicant's qualification and experience information" [7].

The following tables present classifications of Human Resource Ontologies according to eRecruitment domain. This study classifies HR ontologies in respect of single ontology, networked ontology and newly built approaches. While developing ontology some researchers use already available wide spread standards and classifications and some others they developed from the ground. Some of the researchers used matching techniques which we highlighted in the tables, so, we surveyed those kinds of issues and presented their study in the following tables.

Table 2: Single ontology based-on widespread standards

\begin{tabular}{|c|c|c|c|c|}
\hline Author/Year & Title & Technique & Solution & Limitation \\
\hline $\begin{array}{l}\text { C. Bizer, R. Heese, } \\
\text { M. Mochol, R. } \\
\text { Oldakowski, R. } \\
\text { Tolksdorf, R. } \\
\text { Eckstein. 2005. }\end{array}$ & $\begin{array}{l}\text { The Impact of } \\
\text { Semantic Web } \\
\text { Technologies on } \\
\text { Job Recruitment } \\
\text { Processes }\end{array}$ & $\begin{array}{l}\text { Semantic similarity } \\
\text { algorithm between } \\
\text { concepts determined by } \\
\text { the concept distance } \\
\text { which is terminological } \\
\text { matching technique. }\end{array}$ & $\begin{array}{l}\text { Proposed ontology for the } \\
\text { HR domain and explained } \\
\text { an implementation of the } \\
\text { required prototypical } \\
\text { infrastructure. }\end{array}$ & $\begin{array}{l}\text { Not focused to talk about } \\
\text { the composition of sub- } \\
\text { ontologies, and according } \\
\text { to the other research } \\
\text { works, skill is a part of } \\
\text { competency ontology. }\end{array}$ \\
\hline
\end{tabular}




\begin{tabular}{|l|l|l|l|l|}
\hline $\begin{array}{l}\text { Malgorzata } \\
\text { Pashol, Elena } \\
\text { Simperl. 2006 }\end{array}$ & $\begin{array}{l}\text { Practical } \\
\text { Guidelines for } \\
\text { building } \\
\text { semantic } \\
\text { eRecruitment } \\
\text { applications. }\end{array}$ & None. & $\begin{array}{l}\text { Built Human Resource } \\
\text { ontology to supply the } \\
\text { intelligence of semantic } \\
\text { matching technologies } \\
\text { into current e-recruitment } \\
\text { applications . }\end{array}$ & $\begin{array}{l}\text { Not focused to talk about } \\
\text { the composition of sub- } \\
\text { ontologies and they do not } \\
\text { propose any model. }\end{array}$ \\
\hline $\begin{array}{l}\text { Dorn, J.; Naz, T.; } \\
\text { Pichlmair, M. 2007 }\end{array}$ & $\begin{array}{l}\text { Ontology } \\
\text { Development for } \\
\text { Human Resource } \\
\text { Management. }\end{array}$ & None & $\begin{array}{l}\text { Designed two dissimilar } \\
\text { projects: a meta-search } \\
\text { engine for searching } \\
\text { about jobs in job portals } \\
\text { and for university } \\
\text { competence management } \\
\text { system to analyze the } \\
\text { competence of student } \\
\text { profiles. }\end{array}$ & $\begin{array}{l}\text { Focused nothing much for } \\
\text { recruitment ontologies } \\
\text { instead focused not } \\
\text { implemented any } \\
\text { information system to } \\
\text { prove the projects. }\end{array}$ \\
\hline $\begin{array}{l}\text { Tabbasum Naz, et } \\
\text { al.,2010 }\end{array}$ & $\begin{array}{l}\text { Configurable } \\
\text { Meta-Search in } \\
\text { the job domain }\end{array}$ & $\begin{array}{l}\text { Used terminlogical- } \\
\text { level techniques, } \\
\text { structure-level } \\
\text { techniques and } \\
\text { ontology-based } \\
\text { techniques }\end{array}$ & $\begin{array}{l}\text { configurable meta-search } \\
\text { engine for eRecruitment } \\
\text { to search jobs as a job } \\
\text { search engine. }\end{array}$ & $\begin{array}{l}\text { The study lacks details of } \\
\text { sub-ontology } \\
\text { development. }\end{array}$ \\
\hline
\end{tabular}

Table 2 demonstrates Ontology matching based-on Standards and Classifications for single ontology; however, to create HR ontology they used to integrate some existing widespread standards and classifications containing clear and wellrecognized descriptions of occupational titles, associated skills and qualifications mostly in national scope. After creating, it is ready to be deployed in eRecruitment applications in order to have managing electronically available job postings and candidate profiles.

Table 3: Networked ontology based-on widespread standards

\begin{tabular}{|c|c|c|c|c|}
\hline Author/Year & Title & Technique & Solution & Limitation \\
\hline $\begin{array}{l}\text { Valle, E.D., } \\
\text { Cerizza, D., Celino, } \\
\text { I., et. al. } 2008 .\end{array}$ & $\begin{array}{l}\text { SEEMP: A Semantic } \\
\text { Interoperability } \\
\text { Infrastructure for e- } \\
\text { government services in } \\
\text { the employment sector. }\end{array}$ & None & $\begin{array}{l}\text { Proposed an approach } \\
\text { relies on the idea of } \\
\text { services and semantics } \\
\text { to allow information } \\
\text { sharing among many } \\
\text { public and private } \\
\text { Employment services } \\
\text { that exist in Europe. }\end{array}$ & $\begin{array}{l}\text { Not implemented real } \\
\text { world information } \\
\text { system to prove the } \\
\text { idea. }\end{array}$ \\
\hline $\begin{array}{l}\text { Boris Villazón- } \\
\text { Terrazas, Jaime } \\
\text { Ramírez, Mari } \\
\text { Carmen Suárez- } \\
\text { Figueroa, Asunción } \\
\text { Gómez-Pérez. } 2011 \\
\end{array}$ & $\begin{array}{l}\text { A network of ontology } \\
\text { networks for building } \\
\text { e-employment } \\
\text { advanced systems. }\end{array}$ & None & $\begin{array}{l}\text { Explained } \\
\text { methodological } \\
\text { guideline for building } \\
\text { ontologism. }\end{array}$ & $\begin{array}{l}\text { Not implemented any } \\
\text { information system to } \\
\text { prove the proposed } \\
\text { framework. }\end{array}$ \\
\hline
\end{tabular}

Table 3 presents ontology matching approaches for networked (reference and local) ontologies include local ontologies with language dependant which are associated with the reference ontology in English version with the respect of job offers, and CVs can be mediated from any employment services in the region. However, they used to create HR ontology (for local and reference) existing widespread standards and classifications containing clear and wellrecognized descriptions of occupational titles, associated skills and qualifications. 
Table 4: Ontologies based-on newly-built approaches and its associated matching algorithms

\begin{tabular}{|c|c|c|c|c|}
\hline Author/Year & Title & Technique & Solution & Limitation \\
\hline $\begin{array}{l}\text { L. Yahiaoui, et al., } \\
2006\end{array}$ & $\begin{array}{l}\text { Semantic Annotation } \\
\text { of Documents Applied } \\
\text { to e-recruitment }\end{array}$ & $\begin{array}{l}\text { Used semantic } \\
\text { matching computation } \\
\text { coefficient as matching } \\
\text { algorithm which is } \\
\text { terminological } \\
\text { matching technique. }\end{array}$ & $\begin{array}{l}\text { Proposed a scenario of } \\
\text { automatic } \\
\text { eRecruitment web } \\
\text { which the applications } \\
\text { and job descriptions } \\
\text { matched through } \\
\text { semantic annotation } \\
\text { and indexing based on } \\
\text { competency profiles. }\end{array}$ & $\begin{array}{l}\text { Not implement as a } \\
\text { real world prototype to } \\
\text { validate the proposed } \\
\text { model. }\end{array}$ \\
\hline $\begin{array}{l}\text { Mochol, M.; } \\
\text { Jentzsch, et al., } \\
2007 .\end{array}$ & $\begin{array}{l}\text { Suitable employees } \\
\text { wanted? Find them } \\
\text { with semantic } \\
\text { techniques. }\end{array}$ & None & $\begin{array}{l}\text { Proposed eRecruitment } \\
\text { based on semantic } \\
\text { web. They adopted } \\
\text { ontology from } \\
\text { Knowledge nets. }\end{array}$ & $\begin{array}{l}\text { Not focused much } \\
\text { about ontology } \\
\text { components and their } \\
\text { development. }\end{array}$ \\
\hline $\begin{array}{l}\text { Fazel-Zarandi, M.; } \\
\text { Fox, M.S. } 2009\end{array}$ & $\begin{array}{l}\text { Semantic } \\
\text { Matchmaking for Job } \\
\text { Recruitment: An } \\
\text { Ontology-Based } \\
\text { Hybrid Approach }\end{array}$ & $\begin{array}{l}\text { Node-based semantic } \\
\text { similarity measure } \\
\text { which is } \\
\text { terminological } \\
\text { matching technique }\end{array}$ & $\begin{array}{l}\text { HR ontology is } \\
\text { presented in this work } \\
\text { where they propose an } \\
\text { ontology-based hybrid } \\
\text { approach to efficiently } \\
\text { match job seekers and } \\
\text { job descriptions. }\end{array}$ & $\begin{array}{l}\text { Not mentioned the } \\
\text { composition of sub- } \\
\text { ontologies or does not } \\
\text { propose any model. }\end{array}$ \\
\hline $\begin{array}{l}\text { Chaoxiang Chen, et } \\
\text { al., } 2009\end{array}$ & $\begin{array}{l}\text { Design and } \\
\text { Implementation of } \\
\text { SMS Employment } \\
\text { Agent Based on } \\
\text { Ontology }\end{array}$ & $\begin{array}{l}\text { Concept compatible } \\
\text { matching algorithm } \\
\text { which is } \\
\text { terminological } \\
\text { matching technique }\end{array}$ & $\begin{array}{l}\text { Presented SMS } \\
\text { recruitment web } \\
\text { service using ontology } \\
\text { and agent systems. }\end{array}$ & $\begin{array}{l}\text { Not focused to talk } \\
\text { about ontology } \\
\text { components and their } \\
\text { development. }\end{array}$ \\
\hline $\begin{array}{l}\text { Lv Hexin; Zhu } \\
\text { Bin;, } 2010\end{array}$ & $\begin{array}{l}\text { Elastic Information } \\
\text { Matching Technology } \\
\text { and its Application in } \\
\text { Electronic Recruitment }\end{array}$ & $\begin{array}{l}\text { Used semantic } \\
\text { similarity algorithm } \\
\text { determined by distance } \\
\text { of a concept tree } \\
\text { structure, it is both } \\
\text { terminological and } \\
\text { structural. }\end{array}$ & $\begin{array}{l}\text { Presented an approach } \\
\text { to develop ontology } \\
\text { based framework, its } \\
\text { semantic matching } \\
\text { similarity algorithm. }\end{array}$ & $\begin{array}{l}\text { Not focused details of } \\
\text { domain ontology and } \\
\text { real world } \\
\text { implementation } \\
\text { prototype. }\end{array}$ \\
\hline
\end{tabular}

Table 4 presents ontology matching based-on newly built ontology approaches and their associated matching algorithms which most of the researches used skill ontology and its matching criteria. They built HR ontology by themselves especially skill ontology in order to apply eRecruitment application using its respective matching algorithms.

\section{DISCUSSION AND LIMITATIONS}

\subsection{Discussion}

eRecruitments are becoming progressively more important aspect with the development of semantic web technologies, so semantic web is a very effective communication vehicle for eRecruitment which based on ontology and ontology matching techniques in order to provide a platform necessary to locate and match candidates for the job and position offered. However, the first step to develop eRecruitment is to create Human Resource Ontology which its main concept is based on applicant, employer, job description and profile. The Interoperability between employer's job description and candidate's profile are based on set of existing widespread standard vocabularies which provide collective concepts for describing occupational titles, required skills and educational qualifications.
Apart from the existing widespread standards and classification, there are ontologies used to develop towards eRecruitment which have been proposed by some researchers such as ontology-based hybrid approach that matches effectively job seekers and job postings [18], another research conducted has proposed an ontology combined two different projects related to meta-search engine for searching about jobs in job portals and for university competence management system, and other researcher proposed an intelligent recruitment platform using skill ontology-based and its matching algorithm [21]. However, there are several existing ontologies in the HR domain like ProPer Ontology [22], KOWIEN Ontology [23], and Knowledge Nets [6]. Moreover, there are number of approaches describing ontologies in the HR domain, each of them solving with a unique problem. HR ontology can be classified into single, networked and newlybuilt each of which uses different ontology matching techniques as we presented in the tables above. 


\subsection{Limitations}

As ontologies can be used to represent different domains such as eRecruitment, there is a high need for efficient ontology matching techniques that can allow information to be easily exchanged and matched between different heterogeneous systems according recruitment portals. No unique matching technique can perform well for ontologies across recruitment domains. Instead, a particular technique when adapted to a particular ontology, and its underlying characteristics, such as relation types, structure, and background knowledge provides very good performance in determining correspondences between ontologies such as skill, competency, job offer, profile and organization to be matched. Consequently, this raises concerns for the semantic web, in which heterogeneous ontologies are expected to interoperate for exchanging employee resumes and job postings.

\section{CONCLUSION AND FUTURE WORK}

In this paper, it has been reviewed and presented a number of articles for Human Resource Ontology in eRecruitment domain. The papers described the human resource ontology used within ontology matching approach, which provides means for semantic matching approach to match job seekers and job advertisements in a recruitment domain. Most of the papers used widespread standards and classifications to build ontology. Some of the papers have proposed an intelligent employment framework, while others developed an eRecruitment prototype to validate their models.

However, further research is needed to enhance methods of constructing human resource ontology, utilizing the matching techniques for local ontologies in order to match between an integrated set of ontologies composed to reach the best match between positions and candidates. Moreover, research about the usage of ontology matching techniques in different domains should be performed. Research intended at building sufficiently applicable matching techniques between local ontologies for this domain will improve ontology alignment processes. For finding an accurate ontology matching, exact and desirable similarity dimensions among source ontology elements and target ontology elements should be considered.

\section{REFERENCES}

[1] Swartout, B, Ramesh P, Knight, K and Russ, T, (1997) "Toward distributed use of large-scale ontologies", Symposium on Ontological Engineering of, AAAI 138148.

[2] R.Subhashini, Dr. J. Akilandeswari, (2011), "A Survey on Ontology Construction Methodologies", International Journal of Enterprise Computing and Business System, International Systems, Vol 1 Issue 1.

[3] A. Doan, J. Madhavan, P. Domingos and A. Halevy, (2002), "Learning to map between ontologies on the semantic Web", In: Proceedings of the International World Wide Web Conference (Honolulu), (ACM Press, New York) 662-673.

[4] Department of Computing Science,University of Alberta, (2009), "Ontology Matching approaches in semantic web: A survey", Department of Computing Science,University of Alberta, Edmonton, Canada.
[5] Gal, A. \& Shvaiko, P, (2009), "Advances in Ontology Matching", 'Advances in Web Semantics I: Ontologies Web Services and Applied Semantic Web', pp. 176-198 .

[6] C. Bizer, R. Heese, M. Mochol, R. Oldakowski, R. Tolksdorf, R. Eckstein, (2005), "The Impact of Semantic Web Technologies on Job Recruitment Processes", International Conference Wirtschaftsinformatik (WI), Bamberg, Germany.

[7] García-Sánchez, F., Martínez-Béjar, R., Contreras, L., Fernández-Breis, J. T., \& Castellanos-Nieves, D, (2006), "An ontology-based intelligent system for recruitment", Expert Systems with Applications, 31(2), 248-263.

[8] POPESCU, Marian and POPESCU, Emilia, (XVI/2010), "A Human Resource Ontology for Recruitment", Publication: Annals. Economic Science Series, pp. 896901.

[9] Mohammad Mustafa Taye, (2009), Ontology Alignment Mechanisms for Improving Web-based Searching, Phd Thesis at Faculty of Technology De Montfort University, United Kingdom, England..

[10] C. Maria Keet, (2004), “Aspects of ontology integration".

[11] Malgorzata Mochol, Elena Paslaru, Bontas Simperl, (2006) "Practical Guidelines for building semantic eRecruitment applications", Journal: International Journal of Knowledge Management - IJKM.

[12] Dorn, J.; Naz, T.; Pichlmair, M, ((2007) ), “Ontology Development for Human Resource Management", In Proceedings of the 3rd International Conference on Knowledge Managements.

[13] Tabbasum Naz, Jürgen Dorn and Alexandra Poulovassilis, (2010), "Configurable meta-search in the Job Domain", In: International Journal of Web Engineering and Technology, vol. 6, issue 1, pp. 33-57.

[14] Valle, E.D., Cerizza, D., Celino, I., Fugini, M., Estublier, J., Vega, G., Kerrigan, M., Gómez-PTrez, A., Ramírez, J., Villazón-Terrazas, B., Zhao, G., Cesarini, M., \& Paoli, F. D, (2008), "SEEMP: A Semantic Interoperability Infrastructure for e-government services in the employment sector", In Premier reference source, (pp. 105-126).

[15] Boris Villazón-Terrazas, Jaime Ramírez, Mari Carmen Suárez-Figueroa, Asunción Gómez-Pérez, (2011), “A network of ontology networks for building eemployment advanced systems", Journal: Expert Systems with Applications, 38-13612-13624.

[16] L. Yahiaoui, et al, (2006), "Semantic Annotation of Documents Applied to e-recruitment", Proceedings of SWAP the 3rd Italian Semantic Web Workshop, Publisher: Citeseer, Pages: 1-6.

[17] Mochol, M.; Jentzsch, A. and Wache, H, (2007 ), "Suitable employees wanted? Find them with semantic techniques", In Proceedings of Workshop on Making Semantics Web For Business at European Semantic Technology Conference (ESTC2007)", Vienna, Austria.

[18] Fazel-Zarandi, M.; Fox, M.S, (2009), "Semantic Matchmaking for Job Recruitment: An Ontology-Based Hybrid Approach", in Proceedings of the 3rd 
International Workshop on Service Matchmaking and Resource Retrieval in the Semantic Web at the 8th International Semantic Web Conference (ISWC 2010), Washington D.C., USA.

[19] Chaoxiang Chen; Jianlong Ding; Guanping Hua; Yourong Chen;, (2009), "Design and Implementation of SMS Employment Agent Based on Ontology", Software Engineering. WCSE '09. WRI World Congress on, vol.3, no., pp.489-492, 19-21.

[20] Lv Hexin; Zhu Bin;, (2010), "Elastic information matching technology and its application in electronic recruitment", Computer-Aided Industrial Design \& Conceptual Design (CAIDCD), IEEE 11th International Conference on, vol.2, no., pp.1582-1585, 17-19 Nov.

[21] Lv, H., \& Zhu, B, (2006), "Skill ontology-based semantic model and its matching algorithm", In the Proceedings of the 7th International Conference on Computer-Aided Industrial Design and Conceptual Design (CAIDCD).

[22] http://ontobroker.semanticweb.org/ontos/proper.html.

[23] L. Dittmann, S. Zelewski, (2004), "Ontology-based Skills Management", In Procedings of the 8th World Multi-conference on Systemics, Cybernetics and Informatics, Vol. IV, 190-195.

[24] P. Shvaiko and J. Euzenat, (2005), "A survey of schemabased matching approaches", Journal on Data Semantics (JoDS), 1.

[25] Castano, S., Ferrara, A., Montanelli, S., Hess, G.N., Bruno, S, (2007), "State of the Art on Ontology
Coordination and Matching", BOEMIE Bootstrapping Ontology Evolution with Multimedia Information Extraction Project, FP6-027538 D4.4.

[26] Sergey Melnik, Hector Garcia-Molina, and Erhard Rahm, (2002), "Similarity Flooding: A Versatile Graph Matching Algorithm and its Application to Schema Matching", In IEEE International Conference on Data Engineering (ICDE), pages 117-128.

[27] Rubo Zhang, Ying Wang, Jing Wang, (2008), "Research on Ontology Matching Approach in Semantic Web", International Conference on Internet Computing in Science and Engineering, IEEE 978-0-7695-3112-0/08.

[28] An-Hai Doan, Jayant Madhavan, Pedro Domingos, and Alon Halevy, (2004), "Ontology Matching: A Machine Learning Approach", In Steffen Staab and Rudi Studer, editors, Handbook on Ontologies, pages 385-516. Springer Verlag.

[29] A. Thor, T. Kirsten, and E. Rahm, (2007), "Instancebased matching of hierarchical ontologies", In The 12th German Database Conference (BTW).

[30] Pavel Shvaiko and J' er 'ome Euzenat, (2012), "Ontology matching: state of the art and future challenges", IEEE TRANSACTIONS KNOWLEDGE AND DATA ENGINEERING,

[31] Mohammed Muzaffar Hussain, Dr. S.K. Srivatsa, (2012), "A Study of Different Ontology Matching System", International Journal of Computer Applications (0975 8887) Volume 37- No.12, January. 